\title{
A Hybrid Dynamical Modelling and Control Approach for Energy Saving of Central Air Conditioning
}

\author{
Yan Zhang $\mathbb{D},{ }^{1,2}$ Yongqiang Liu $\mathbb{D}^{1},{ }^{1}$ and Yang Liu $\mathbb{D}^{1}$ \\ ${ }^{1}$ School of Electric Power, South China University of Technology, Guangzhou, Guangdong, China \\ ${ }^{2}$ Faculty of Development and Educational Technology Centre, Guangdong University of Finance and Economics, \\ Guangzhou, Guangdong, China
}

Correspondence should be addressed to Yang Liu; 1.y96@mail.scut.edu.cn

Received 1 February 2018; Revised 7 June 2018; Accepted 14 June 2018; Published 8 July 2018

Academic Editor: Bin Jiang

Copyright (C) 2018 Yan Zhang et al. This is an open access article distributed under the Creative Commons Attribution License, which permits unrestricted use, distribution, and reproduction in any medium, provided the original work is properly cited.

\begin{abstract}
Currently in China, energy conservation and emission reduction are important initiatives for society. Because of its large proportion of building energy consumption, several methods for building energy conservation have been introduced for central air conditioning. This paper presents a hybrid system for a modelling and control approach. By analysing the cooling capacity transfer process and the electromagnetic properties of pumps, the modelling is performed in a hybrid system framework. Pumps are classified as fixed-frequency pumps, variable-frequency pumps, and switchable pumps; a switch control strategy is used in the chilled water system for supplying cooling capacity. In order to adjust indoor temperature and save electrical energy, the cooling capacity allocation and average temperature methods are presented, which satisfy the goal of optimal control of real-time energy consumption. As a numerical example, the temperature variation and cold regulation processes are simulated. Three rooms are the control objects that lower the setting points, and pumps waste as little electrical energy as possible. The results show $49.4 \%$ of water pump power consumption when compared with constant water volume technology. The modelling and control approach is more advantageous in ensuring the success of reconstruction projects for central air conditioning.
\end{abstract}

\section{Introduction}

Currently, China is facing a series of ecological problems, such as climate change, environmental degradation, and increases in energy consumption. According to the "China Statistical Yearbook 2015", the levels of energy utilization and features of energy consumption remain in a backward predicament of high energy consumption, low efficiency, and serious waste. In 2013, for example, the average power consumption was 148.5 million kWh every day, and the transfer efficiency was $43.12 \%$ [1]. These statistical data show the extensive form of Chinese development, which is far different from that of developed countries. Recently, the Chinese government has made unflinching efforts to build an environmentally friendly society; certainly, the concepts of energy conservation and emission reduction have informed policy orientation.
Central air conditioning accounts for a great proportion of building energy consumption and has considerable opportunities for energy conservation and emission reduction. Thus, research on energy savings for central air conditioning has a significant impact. There are several methods for building energy conservation: manual dispatching based on management view, optimized control schemes based on sample statistics, and technical renovation based on variable water/air volume. In the perspective of management, Liang et al. [2] pointed out the "reasonable energy consumption standard" and "differentiation of buildings". The concepts of "priority buildings" and "benchmarking buildings" were proposed. By evaluation and supervision, an operating plan is made for saving energy. Fong et al. [3] used an approach of evolutionary programming for energy management. The existing operational settings can be improved by suggesting optimized information. Keçebaş and Yabanova [4] studied 
exergy efficiencies of district heating systems by using an artificial neural network technique. Using average weekly data, the performance and characteristics are predicted. In addition, ambient temperature and flow rates are the main factors in thermal optimization. These are extensive measures with conspicuous disadvantages. Manual dispatching relies on the experience and subjectivity of operators and lacks accuracy. According to the day, season, climatic characteristics, and other factors, the method of the optimized control scheme satisfies the requirements to some extent but is not suited for changes of some random loads, and thus lacks intime adjustment.

Because of uncertain cold loading, variable water/air volume has the advantages of instantaneous adjustment of cooling capacity and energy consumption. Compared with building a new system, technical innovation avoids massive cost and long projects. Moreover, in the air conditioning system, up to $70 \%$ of the power consumption is due to pumps and fans [5]. Obviously, in renewal projects, pumps and fans have great potential for energy savings.

Many investigation reports in the literature show that variable water volume technology is a current focus in our research. There are several optimization methods that can effectively address these problems. These methods are the analytical approach [6-9], direct search method [10], linear quadratic programming [11], nonlinear programming method [12], heuristic optimization algorithm [3, 13, 14], and artificial neural networks [15]. Kaya et al. [6] analysed the influence factors of the effectiveness in pumps and presented an approach for improvement. By using measured data, the potential energy saving opportunities, investment costs, and payback periods are calculated. Lu et al. [7] provided some formulation and analysis based on global optimization technologies towards overall heating, ventilation, and air conditioning (HVAC) systems. For new urban development, Chow et al. [8] predicted thermal demands and outlined an energy modelling methodology and decision approach to derive the most desirable scheme for a given project. Sheng and Duanmu [9] presented electricity consumption and economic analyses. Lu et al. [13] and Nassif et al. [14] used a genetic algorithm to optimize the models of components in HVAC systems. Fong et al. [3] adopted a robust evolutionary algorithm for system optimization.

Control strategies include temperature difference and pressure difference control methods. Wang and Burnett [16] developed an online control strategy to optimize the speed of variable-speed condenser cooling water pumps by adjusting the pressure set point. The adaptive strategy is used to identify the parameters with sampling at each step. Zhao et al. [5] focused on extreme value analysis for parallel variablefrequency hydraulic pumps in central air conditioning systems. He used a variable differential pressure set point control strategy to respond to fast load variations and explored the optimal number of operating units of parallel variablefrequency pumps. This method obtains electricity savings of $15.8 \%$ and $4 \%$ compared with a single-pump operation scheme and dual-pump operation scheme, respectively.

Moreover, some experimental and applicable results show advantages towards the method of technical renovation.
Anderson et al. [17] built an experimental system for HVAC control and obtained some ideal results. Qu et al. [18] proposed a multilayer feed-forward artificial neural network based on a Back Propagation (BP) algorithm and used MATLAB implements to design and train an energy consumption prediction model of a micro urban building. Lu et al. [19] proposed an optimization plan in building sections. For engineering applications, there are persuasive architectures in Hong Kong [20, 21] and Da Lian [22].

In these studies, pure continuous or discrete control systems are used for the control of the entire air conditioning system. However, the constant frequency pumps, variablefrequency pumps, and switching pumps in the chilled water system constitute a hybrid system. The frequency conversion operation and switching action of the pumps reflect the continuous and discrete dynamics, respectively. Therefore, the methods can hardly reflect the accuracy and applicability of the system structure and control process, nor an ideal energy saving effect. In addition, the electromagnetic properties of pumps are elided normally, although the hydraulic and thermodynamic characteristics are considered. Because the mathematical model of a pump motor is a high-order, nonlinear multivariable system with strong coupling effects, the variable-frequency, quadratic regression empirical formulas or simple proportional expressions cannot reflect the dynamics of motor appropriately. Compared with the pressure difference control strategy, the temperature difference control method is superior in energy saving.

In this paper, a hybrid model was used in the modelling of the chilled water system in a central air conditioning system. Variable-frequency pumps and switchable pumps denote continuous and discrete control inputs, respectively. Based on the model, a hybrid dynamical control strategy was proposed for variable volume control and better energy saving performance. This model reflects the actual working conditions of central air conditioning water systems, especially in aspects of pump movement and water flow change characteristics. Problems such as time variability, multivariable, nonlinearity, and uncertainty are considered, and the energy saving performance of the proposed control method is exhibited.

The modelling and controlling of the system are shown as follows: first, an optimized pump model of speed adjustment based on vector control was developed, which prefers electromagnetic properties and the torque response effect. In addition, considering the load characteristics of the water system, we regulate the water volume of pumps by vector control instantaneously. Second, the cooling capacity transfer process is described, with thermodynamic properties throughout the framework. The measure of constant temperature difference is used in the model. Third, we use switching control strategy, cooling capacity allocation, and average temperature methods in order to obtain the hybrid dynamical property by volume adjusting and pump switching (on/off). Thus, we not only realise variable volume control, but also satisfy the energy saving requirement. Finally, a numerical example illustrates the control process and situation of energy savings.

This paper is organized as follows. In Section 2, the mathematical description of hybrid system is presented. 


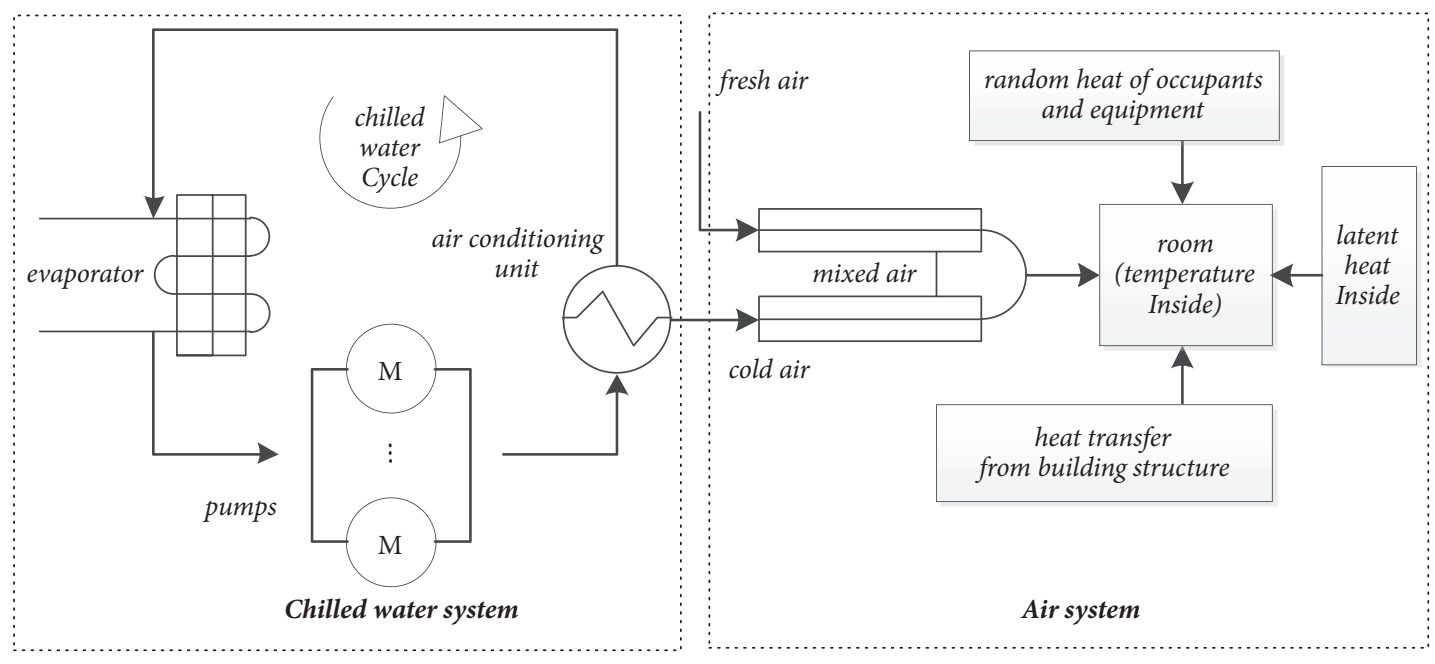

FIGURE 1: Cooling capacity transfer and temperature change processes.

In Section 3, hybrid system modelling of cooling capacity transfer process between water system and wind system is expressed. In Section 4, the hybrid dynamical control strategy used in energy saving for chilled water system is presented. In Section 5, a simulation example is given to illustrate the modelling and control processes. Section 6 concludes the paper.

\section{Mathematical Description of Hybrid System}

The hybrid system is described by

$$
\begin{aligned}
\dot{x}_{\sigma_{i}(\tau)} & =A_{i} x(\tau)+B_{i} u(\tau)+f_{i} \\
y_{i} & =C_{i} x(\tau)
\end{aligned}
$$

for

$$
\left[\begin{array}{l}
x_{i} \\
u_{i}
\end{array}\right] \in X_{i}
$$

where $x_{i} \in R^{n}$ denotes state variables, $u_{i} \in R^{m}$ denotes control variables, $f_{i}$ denotes constant vector, and $y_{i}$ denotes output. $A_{i}$ and $C_{i}$ are state matrices; $B_{i}$ is input matrix. $\bigcup_{i=0}^{n} X_{i}$ are convex polyhedra in the input+state space, and $X_{i} \cap X_{j}=\varnothing$ denotes possibly being unbounded by each other. $X_{i}$ implies the $i$ th subsystem, and $i=0,1, \ldots, N$ implies $N+1$ subsystems. $\bigcup_{i=0}^{n} X_{i}=X$ implies that all subsystems constitute the whole system. $\sigma_{i}(\tau), \tau \in[0,+\infty)$ denotes the switching law of the hybrid system. Several differential or difference equations as subsystems constitute a hybrid system, and they obey the switching law. The law decides the key issues, such as switching time, switching state, and switching orientation. The system switches among the $N+1$ subsystems and selects only one at any time.

\section{Modelling the Framework of the Cooling Capacity Transfer and Temperature Change Processes}

In the air conditioning system, the cooling capacity transfers from chiller unit to chilled water system by evaporator. The pumps drive water as cycle in the chilled water system, and send cooling capacity to air condition unit for exchanging from chilled water system to air system. After mixing with fresh air, the cold air is sent to air conditioning room to drop the temperature. In the process of temperature change in air conditioning room, the heat balance is influenced by several aspects: cold air, random heat of occupants and equipment, latent heat inside, and heat transfer from building structure. The processes of the cooling capacity transfer and temperature change is shown in Figure 1.

This paper uses constant air volume and variable water volume/constant temperature difference measures to transfer cooling capacity. In chilled water system, switching and variable-frequency behaviours of pumps adjust the flow for saving energy, which denote the discrete and continuous time process, respectively. So we give an equation to show the heat balance as follows:

$$
\begin{aligned}
C_{a} m_{a} \frac{d \theta}{d \tau}= & -\varepsilon C_{w} \Delta \theta\left(q_{b}+q_{G}+k q_{s w}\right) \\
& -\left(1-R_{r}\right) q_{s a} C_{a} \theta+\left(1-R_{r}\right) q_{s a} C_{a} \theta_{\text {out }} \\
& +Q_{r d}+Q_{q r}-\sum K_{j} A_{j} \theta+\sum K_{j} A_{j} \theta_{j}
\end{aligned}
$$

On the left side of the equation, $C_{a} m_{a}(d \theta / d \tau)$ means the time differential of the heat capacity of a room. On the left side of the equation, $-\varepsilon C_{w} \Delta \theta\left(q_{b}+q_{G}+k q_{s w}\right)$ means the cooling capacity for chilled water system; $-\left(1-R_{r}\right) q_{s a} C_{a} \theta$ and $\left(1-R_{r}\right) q_{s a} C_{a} \theta_{\text {out }}$ mean the cooling capacity from return and fresh air systems, respectively; $Q_{r d}$ means random heat of occupants and equipment; $Q_{q r}$ means latent heat inside; 
$-\sum K_{j} A_{j} \theta+\sum K_{j} A_{j} \theta_{j}$ means heat transfer from building structure.

The description of the symbol can be seen in the subsequent chapters and in Nomenclature.

Towards motor model of variable-frequency pump, we use a direct torque control model to build and design the closed-loop control of torque and flux linkage; but for constant frequency pump, we use constant to describe it. By building relationship of torque with water flow volume, we get equations of state space for the whole process of the model at last.

3.1. Modelling the Cooling Capacity Transfer Process. It is known that the cold load of central air conditioning is affected by factors such as the structure and materials of a building, outdoor weather parameters, indoor lighting, radiating equipment, and number of occupants. In order to describe the dynamic process, we consider the area $A_{i}$ and temperature $\theta_{i}$ of walls, windows, and roof, according to the different materials, and use the heat transfer coefficient $K_{i}$, accordingly. We use $Q_{r d}$ to indicate the random changing heat by equipment and people. The supply air carries cooling capacity inside the building to balance the heat.

The dynamic thermal balance equation in a room is

$$
C_{a} m_{a} \frac{d \theta}{d \tau}=q_{\mathrm{sa}} C_{a}\left(\theta_{s a}-\theta\right)+\sum K_{j} A_{j}\left(\theta_{j}-\theta\right)+Q_{r d}
$$

where $C_{a}$ is the specific heat of air, $\theta$ is the temperature inside, $m_{a}$ is the mass inside, $q_{s a}$ is the sending air volume, and $\theta_{s a}$ is the sending air temperature.

In the cooling capacity transfer process, some of the cold is lost; we set the transfer efficiency as $\varepsilon$ from water system $Q_{w}$ to air system $Q_{a}(0 \leq \varepsilon \leq 1)$, so we easily obtain the equation $\varepsilon Q_{w}=Q_{a}$. In view of the factors of latent heat load $Q_{q r}$ and sensible heat load $Q_{x r}$, we obtain

$$
\varepsilon Q_{w}=Q_{a}=Q_{q r}+Q_{x r}
$$

The media of the water system and air system are water and air, respectively; by the temperature difference $\Delta \theta$, the cooling capacity is transferred. Thus, the equation becomes

$$
\varepsilon q_{w} C_{w} \Delta \theta=q_{s a} C_{a}\left(\theta-\theta_{s a}\right)+Q_{q r}
$$

where $C_{w}$ is the specific heat of water, and $q_{w}$ is the water volume.

Because of the return air rate $R_{r}$, the fresh rate obviously is $1-R_{r}$; hereby, the air volume of the test room is divided into return air volume $q_{r t}$ and fresh air volume $q_{f}$. The equation becomes

$$
\begin{aligned}
\varepsilon q_{w} C_{w} \Delta \theta= & \left(1-R_{r}\right) q_{s a} C_{a}\left(\theta_{f}-\theta_{s a}\right) \\
& +R_{r} q_{s a} C_{a}\left(\theta-\theta_{s a}\right)+Q_{q r}
\end{aligned}
$$

The equation can be rewritten as

$$
\theta_{s a}=\theta_{f}\left(1-R_{r}\right)+\theta R_{r}-\frac{C_{w} q_{w} \Delta \theta}{q_{s a} C_{a}}+\frac{Q_{q r}}{q_{s a} C_{a}}
$$

Substituting (8) into (4) obtains

$$
\begin{aligned}
C_{a} m_{a} \frac{d \theta}{d \tau}= & -\varepsilon q_{w} C_{w} \Delta \theta \\
& +\left[\left(R_{r}-1\right) q_{s a} C_{a}-\sum K_{j} A_{j}\right] \theta \\
& +\left(1-R_{r}\right) q_{s a} C_{a} \theta_{f}+\sum K_{j} A_{j} \theta_{j}+Q_{r d} \\
& +Q_{q r}
\end{aligned}
$$

In the chilled water system, we use the variable flow volume and constant temperature difference measures. With regard to variable flow volume, we should notice that the minimum volume is not lower than $40 \%$ of the rated value; otherwise, the energy efficiency of the pump would decay sharply. Thus, whatever kinds of pumps are operating, the whole water flow volume should be between $40 \%$ and $100 \%$. In the system, the pumps are divided into three kinds: fixed pumps, variablefrequency pumps, and switchable pumps. The fixed pumps and variable-frequency pumps always operate; the switchable pumps either operate or not because of the cold loading. Both fixed pumps and switchable pumps are fixed-frequency; to distinguish them, they are simply called fixed pumps and switchable pumps, respectively.

According to the three kinds of pumps, the water flow volume is expressed as

$$
q_{w}=q_{g}+q_{b}+k q_{s w}
$$

Here, $q_{g}$ is a constant that indicates the flow volume of all the fixed pumps, $q_{b}$ is a state variable that indicates the flow volume of the variable-frequency pumps, $q_{s w}$ is a constant that indicates the flow volume of a switchable pump, and $k$ is the number of operating switchable pumps. Therefore we substitute (10) into (9) to obtain (3).

3.2. Motor Model of Variable-Frequency Pump. Most variable-frequency pumps are asynchronous AC motors in air conditioning systems. We use a stator flux-oriented direct torque control-space vector pulse width modulation (DTCSVPWM) model to build and design the closed-loop control of torque and flux linkage. The features of DTC-SVPWM are that the controller computes the suitable stator voltage vector, and the method of SVPWM modulation generates the voltage vector to control torque and flux linkage. The structure is shown in Figure 2.

The $M-T$ coordinate system is a synchronous revolution according to the stator flux orientation; the direction of the $M$-axis is the same as that of the stator flux linkage, and we use $u_{s M}^{*}$, which is output from the flux linkage $P I$ adjuster to control the amplitude of the stator flux linkage $\Psi_{s}$. The direction of the $T$-axis is perpendicular to stator flux linkage; we use $u_{s T}^{*}$, which is output from the torque PI adjuster, to control the rotational speed of the stator flux linkage and then electromagnetic torque $T_{e}$. We obtain $u_{s}^{*}$ from the transformation of coordinates and input it to the SPVWM to control the motor. Via double closed-loop feedback control, flux linkage and electromagnetic torque are compared with the setting values and accurately adjusted. The 


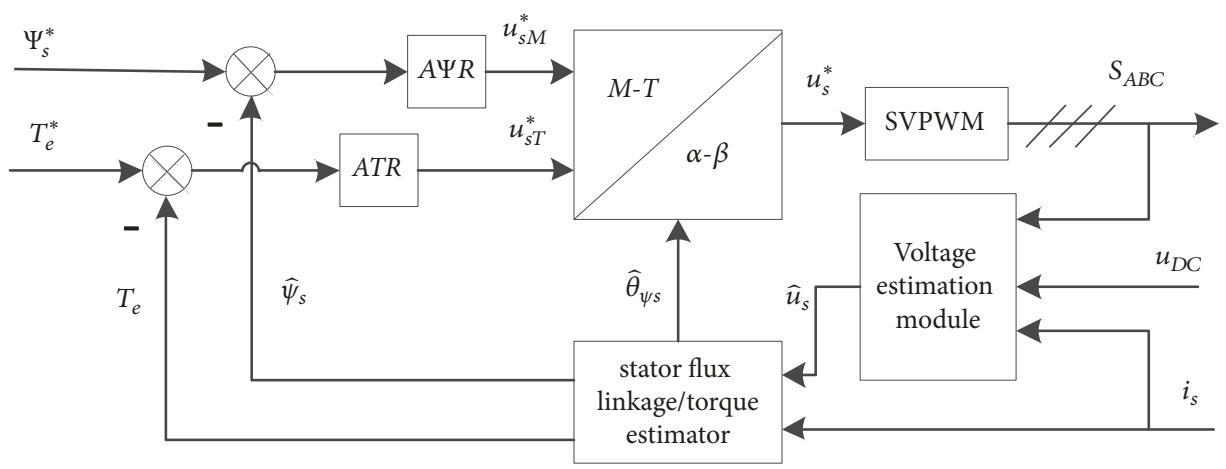

FIGURE 2: Motor model.

voltage estimation module estimates the actual stator voltage vector according to switch status signal $S_{A B C}$ and measured busbar voltage $u_{D C}$.

The simplified equations of stator voltage and torque are

$$
\begin{aligned}
\frac{d \Psi_{s}}{d \tau} & =u_{s M}-r_{s} i_{s M} \\
T_{e} & =\frac{1}{r_{s}} n_{p} \Psi_{s}\left(u_{s T}-\omega_{s} \Psi_{s}\right)
\end{aligned}
$$

It is apparent that the input variables and output variables have coupling relationships, so we cannot use $u_{s M}$ and $u_{s T}$ to achieve independent control with $\Psi_{s}$ and $T_{e}$, respectively. Therefore, a new variable $u_{\Psi}$ must be introduced for decoupling. Let

$$
\begin{aligned}
& u_{\Psi}=u_{s M}-r_{s} i_{s M} \\
& u_{T}=\Psi_{s}\left(u_{s T}-\omega_{s} \Psi_{s}\right)
\end{aligned}
$$

After decoupling, the transfer function is a proportional component from $u_{T}$ to $T_{e}$; the transfer function is

$$
G_{T}(s)=\frac{T_{e}(s)}{u_{T}(s)}=\frac{n_{p}}{r_{s}}
$$

The dynamic structure of the torque control loop is shown in Figure 3. In the figure, there is an inertial component and a proportional component. The filter time constant $T_{f T}$ is the same as the feedback smoothing time constant; the integral time constant of the torque controller is $T_{i T}$.

We use an integral controller for torque adjustment.

$$
G_{A T R}(s)=\frac{1}{s T_{i T}}
$$

Thus, the torque control loop is simplified as

$$
G_{T-0}(s)=\frac{n_{p}}{s T_{i T}\left(1+s T_{f T}\right) r_{s}}
$$

3.3. Building the Relationship of Torque with Water Flow Volume of a Variable-Frequency Pump. In general, the water volume $q$ is in proportion to speed $n$ of a pump in a water

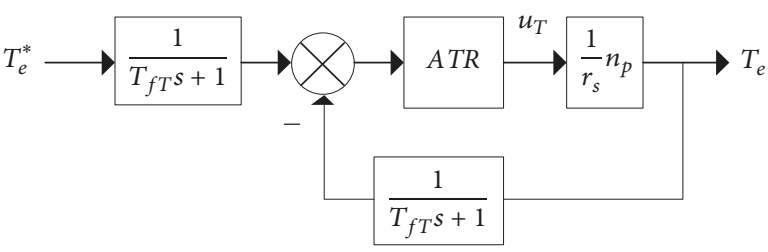

Figure 3: Torque control loop.

system, so it is obvious that $q / q_{0}=n / n_{0}$, where $q_{0}$ is the rated water volume and $n_{0}$ is the rated speed. Using motion equation, where $J$ is the rotational inertia, $T_{e}$ is the torque, and $T_{L}$ is the load torque, the torque is obtained by

$$
T_{e}=T_{L}+J \cdot \frac{n_{0}}{q_{0}} \cdot \frac{d q}{d \tau}
$$

In addition, the load of the pumps conforms to a quadratic proportion, where $T_{L 0}$ is the rated load torque. As an equation:

$$
\frac{T_{L}}{T_{L 0}}=\frac{n^{2}}{n_{0}^{2}}
$$

Thus the relationship from torque to water flow volume is built. Combining (17) with (10), we build the state space equation to show the whole control process of the pumps. Here, with $x_{1}=\theta$ as the inside temperature and $x_{2}=q_{b}$ as water flow volume of the variable-frequency pump, $x_{1}$ and $x_{2}$ are state variables. With $u=T_{e}$ as a control variable, we set $y=x_{1}$ as the output variable. Figure 4 shows the state space.

Thus, the coefficients of the state space equation are

$$
\begin{aligned}
& A=\frac{(w-1) q_{n} c_{a}-\sum K_{i} A}{C_{z}} \\
& B=-\frac{\varepsilon c_{w} \Delta \theta}{C_{z}} \\
& E \\
& =\frac{(1-w) q_{s a} c_{a} \theta_{\text {out }}+\sum K_{i} A_{i} \theta_{i}+Q+Q_{q r}-q_{G} \varepsilon c_{w} \Delta \theta}{C_{z}}
\end{aligned}
$$




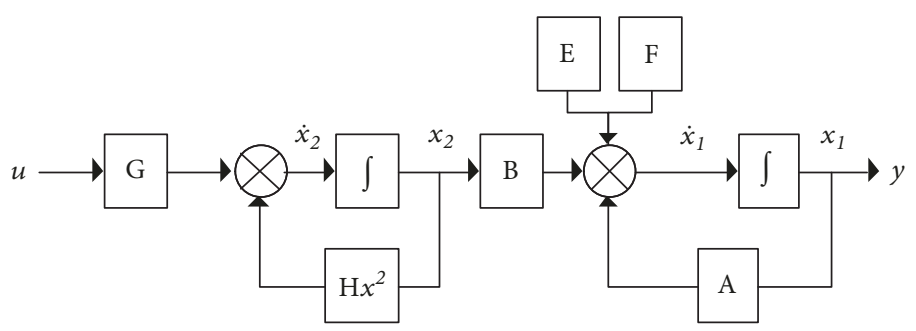

Figure 4: State space.

$$
\begin{aligned}
F_{i} & =-\frac{k q_{N} \varepsilon c_{w} \Delta \theta}{C_{z}} \quad[k=1,2, \ldots, n] \\
G & =\frac{1}{J} \cdot \frac{q_{0}}{n_{0}} \\
H & =\frac{T_{L 0}}{n_{0}^{2}} \cdot \frac{1}{J} \cdot \frac{q_{0}}{n_{0}}
\end{aligned}
$$

Combining these equations and coefficients; we get the equations of state space:

$$
\begin{aligned}
& \dot{x}=\left(\begin{array}{ll}
A & B \\
0 & 0
\end{array}\right) x+\left(\begin{array}{c}
0 \\
H
\end{array}\right) x^{2}+\left(\begin{array}{l}
0 \\
G
\end{array}\right) u+\left(\begin{array}{c}
E+F \\
0
\end{array}\right) \\
& y=\left(\begin{array}{l}
1 \\
0
\end{array}\right) x
\end{aligned}
$$

3.4. Mathematical Power Models of Pumps. According to the electromagnetic property of a variable-frequency pump, the output mechanical power of the pump is

$$
P_{o p}=\eta_{b} T_{e} \omega=\frac{\eta_{b} T_{e} n}{9550}
$$

$\eta_{b}$ is the factor converted from motor power into output mechanical power, $0 \leq \eta_{b} \leq 1$, and $\omega$ is angular velocity.

The power of a fixed pump is $P_{g}$, and the power of switchable pumps is $P_{s w}$. Both of these kinds of pumps operate at constant frequency, so we consider them operating at constant power. Thus we get the total power of the pumps:

$$
P_{\text {total }}=G P_{g}+P_{b}+k P_{s w}
$$

$G$ is the total number of fixed pumps and $k$ is the number of operating switching pumps.

\section{Hybrid Dynamical Control Strategy}

4.1. Target of Optimal Hybrid Control for Central Air Conditioning. The goal of optimal control for central air conditioning is to minimise the power of the chilled pumps; further, the inside temperature $\theta$ should be close to the setting temperature $\theta_{\text {set }}$. We obtain the target function

$$
\begin{aligned}
& \min J= \int_{\tau_{0}}^{\tau_{f}} P_{\text {total }} d \tau \\
&= \int_{\sigma_{i}(\tau)}^{\tau_{1}} P_{\text {total }} d \tau+\int_{\sigma_{1}(\tau)}^{\tau_{2}} P_{\text {total }} d \tau+\ldots \\
&+\int_{\tau_{n-1}(\tau)}^{\tau_{f}} P_{\text {total }} d \tau=\sum_{i=0}^{n-1} \int_{\sigma_{n}(\tau)}^{\tau_{1+i}} P_{\text {total }} d \tau \\
& \sigma_{i+1}(\tau)
\end{aligned}
$$

where $\tau_{f}=\tau_{n}$. Due to the switching behaviours, the system is divided into some subsystems in different time intervals, namely, $\left[\tau_{0}, \tau_{1}\right],\left[\tau_{1}, \tau_{2}\right], . .,\left[\tau_{n-1}, \tau_{f}\right]$. The switching sequence is produced at switching time $\tau_{i}$, and the switching law $\sigma_{i}$ and $\tau_{i}$ are one-to-one correspondence.

Equation (22) means that (i) the target function is to find the minimum value of energy consumption of pumps on time interval $\left[\tau_{0}, \tau_{f}\right]$; (ii) the function is divided into several parts, and we calculate the integration on each time interval; (iii) the sum of all integration terms is the minimum of the objective function.

Remarks 1 .

(1) $i$ is finite.

(2) Switching law is state-independent, so the length of each time interval is not the same.

(3) We simply consider the requirement of energy saving, and the humidity is not concerned in this work.

4.2. Developing the Switching Control Strategy. Variable water flow is realised by variable-frequency regulation of variablefrequency pumps and switching control of switchable pumps. For the water flow volume of the variable-frequency pump, the feedback closed loop can be used in the system for accurate adjustment. For the switching pumps, we propose an algorithm for deployment. According to the changing cold load, we set the switching condition and orientation. The switching law is a simple and economic mode in reconstruction engineering that avoids complex processes and computing time. It is shown in Figure 5.

The switching strategy is based on state dependence. The switching behaviour occurs simply by satisfying the state 


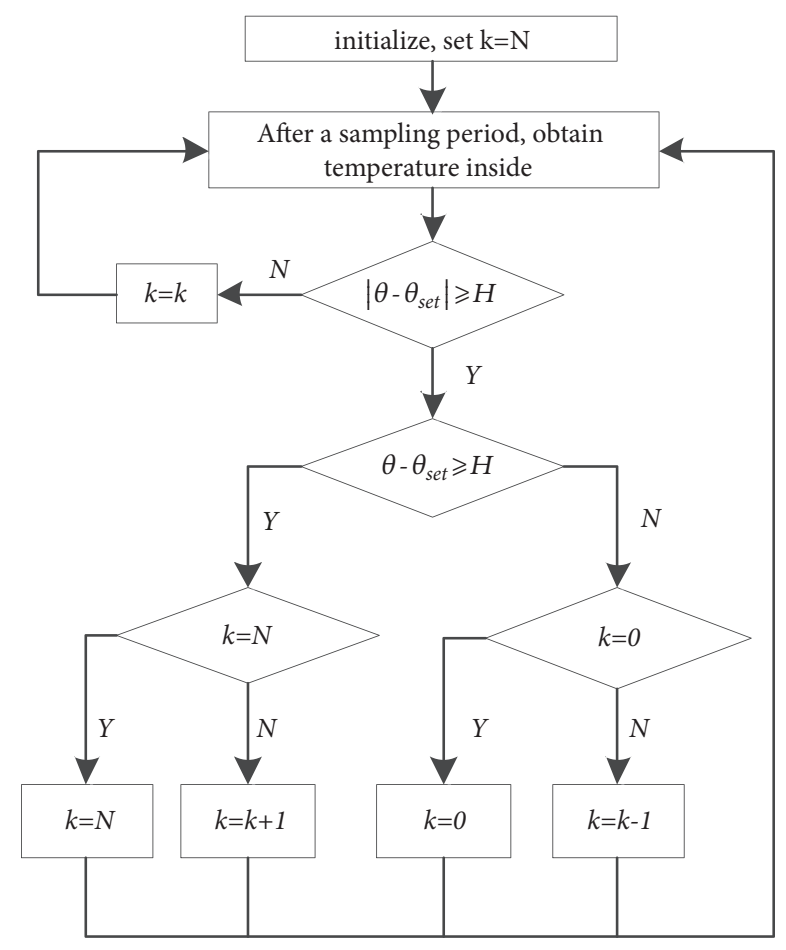

FIGURE 5: Control strategy of switching pumps.

judgement. In other words, once the real-time sampling value is beyond the setting threshold value $|H|$, the system will switch. At the initial time, $k$ is set to the maximum value $N$. After each sampling period (constant), the system obtains the inside temperature $\theta$ and compares $\left|\theta-\theta_{\text {set }}\right|$ with $|H|$. If the value is in the setting range, the system will stay in the current subsystem. Otherwise, we will calculate $\left|\theta-\theta_{\text {set }}\right|$. One way is $k+1$, because of $\theta-\theta_{\text {set }} \geq H$, unless $k$ is the maximum; the other is $k-1$, because of $\theta-\theta_{\text {set }} \leq-H$, unless $k$ is the minimum.

Remarks 2.

(1) $\theta_{\text {set }}$ is the inside temperature setting, and $\theta$ is the realtime inside temperature.

(2) $k$ is the number of operating switching pumps.

(3) The maximum number of switching pumps is $N$. If all the switching pumps are operating, the system is close to full capacity.

(4) The minimum number of switching pumps is 0 . If a nonswitching pump is operating, the system is close to optimal energy saving.

(5) Whether switching is on or off, the system obeys one pump at a time. The switching behaviour triggers only one pump.

4.3. Cooling Capacity Allocation and Average Temperature Methods. For a whole building, the framework is modelled with a switching control strategy. In real system, with many rooms with different areas, the cooling capacity requirement and temperature setting need an adaptive method to match. For allocation of cooling capacity, we adopt a weighting factor according to the proportion of thermal capacity in each room. This is a quantitative criterion on the demand side; on the supply side, there is a measure to balance different inside temperatures. The average temperature difference as a feedback signal is used to control the pumps. The switching condition $\left|\theta-\theta_{\text {set }}\right|$ can be modified as

$$
\overline{\left|\theta-\theta_{\text {set }}\right|}=\sum_{1}^{N} \frac{\left|\theta_{i}-\theta_{\text {set }-i}\right|}{N}
$$

The weighting factor is

$$
F_{i}=\frac{C_{Z-i}}{\sum_{1}^{N} C_{Z-i}}
$$

The schematic diagram is shown in Figure 6.

Remarks 3.

(1) $\overline{\left|\theta-\theta_{\text {set }}\right|}$ is the average temperature difference of the building.

(2) $\theta_{i}$ is the real-time temperature inside the $i$ th room; $\theta_{\text {set }-i}$ is the setting temperature inside the $i$ th room. There are $N$ rooms operating by using cooling capacity.

(3) $F_{i}$ is the weighting factor of the $i$ th room for cooling capacity allocation; $C_{Z-i}$ is the thermal capacity of the $i$ th room.

(4) $\sum_{1}^{N} C_{Z-i}$ is the total thermal capacity of the rooms by using cooling capacity.

(5) Obviously, these are based on the quantitative criterion, whatever the average temperature difference or weighting factor.

(6) In view of allocating cooling capacity by weighting factor, the computing method of average temperature difference actually involves the average temperature per cubic meter.

(7) Heat capacity $C_{Z}$ is equal to $C_{a} m_{a}$ for each room.

\section{Numerical Example and Simulation Results}

In this section, we present numerical results from simulations of the chilled water system. Three different rooms are the simulation objects; the cold air is sent to the rooms for reducing the inside temperatures. The supply side uses pumps for sending cold water to the air system by the switching control strategy and cooling capacity allocation method. We use one variable-frequency pump, four switching pumps, and two fixed pumps to transfer chilled water and adjust cooling capacity. The cooling capacity transfer mode of variable water volume and constant air volume is presented. The purpose of the variable water volume is accuracy control and energy saving, via our model and control strategy. The parameters are listed in Table 1.

Simulink 2007 was used for simulating the whole process, where the simulation time was $5000 \mathrm{~s}$. The switching sample time $T_{L}$ of the system was set to $60 \mathrm{~s}$; the system checks the real-time inside temperature each $T_{L}$ and decides the 
TABLE 1: Thermal parameters.

\begin{tabular}{|c|c|c|}
\hline Parameter & Value & Remark \\
\hline$m_{a}(\mathrm{~kg})$ & $67.725,90.3,158.025$ & Rooms A, B, and C, respectively \\
\hline$q_{b}(\mathrm{~kg} / \mathrm{s})$ & 0.02 & \\
\hline$q_{s w}(\mathrm{~kg} / \mathrm{s})$ & 0.013 & \\
\hline$q_{s a}(\mathrm{~kg} / \mathrm{s})$ & $0.655,0.655,0.655$ & Rooms A, B, and C, respectively \\
\hline$q_{g}(\mathrm{~kg} / \mathrm{s})$ & 0.025 & \\
\hline$A_{i}\left(\mathrm{~m}^{2}\right)$ & $36,8,0$ & Room A \\
\hline$A_{i}\left(\mathrm{~m}^{2}\right)$ & $52,9,0$ & Room B \\
\hline$A_{i}\left(\mathrm{~m}^{2}\right)$ & $66,12,6$ & Room C \\
\hline$C_{a}(\mathrm{~J} / \mathrm{kg} * \mathrm{k})$ & 1010 & \\
\hline$C_{w}(\mathrm{~J} / \mathrm{kg} * \mathrm{k})$ & 4180 & \\
\hline$F$ & $0.214,0.286,0.5$ & Rooms A, B, and C, respectively \\
\hline$H\left({ }^{\circ} \mathrm{C}\right)$ & 0.2 & \\
\hline$K_{f b}$ & $0.0037,0.286,0.0026$ & Rooms A, B, and C, respectively \\
\hline$K_{f b t}$ & -0.061 & Whole system \\
\hline$K_{j}\left(\mathrm{~W} / \mathrm{m}^{2} * \mathrm{k}\right)$ & $0.049,0.051,0.05$ & \\
\hline$Q_{q r}(J)$ & $19,28,31$ & Rooms A, B, and C, respectively \\
\hline$R_{r}$ & 0.82 & \\
\hline$\Delta \theta\left({ }^{\circ} \mathrm{C}\right)$ & 5 & \\
\hline$\varepsilon$ & 0.86 & \\
\hline$\theta_{i n i}\left({ }^{\circ} \mathrm{C}\right)$ & $30,30,30$ & Rooms A, B, and C, respectively \\
\hline$\theta_{f}\left({ }^{\circ} \mathrm{C}\right)$ & $25,25,25$ & Rooms A, B, and C, respectively \\
\hline$\theta_{j}\left({ }^{\circ} \mathrm{C}\right)$ & $35,35,36$ & Room A \\
\hline$\theta_{j}\left({ }^{\circ} \mathrm{C}\right)$ & $35,35,36$ & Room B \\
\hline$\theta_{j}\left({ }^{\circ} \mathrm{C}\right)$ & $35,35,36$ & Room C \\
\hline$\Theta_{\text {set }}\left({ }^{\circ} \mathrm{C}\right)$ & $25.8,26.1,25.9$ & Rooms A, B, and C, respectively \\
\hline
\end{tabular}

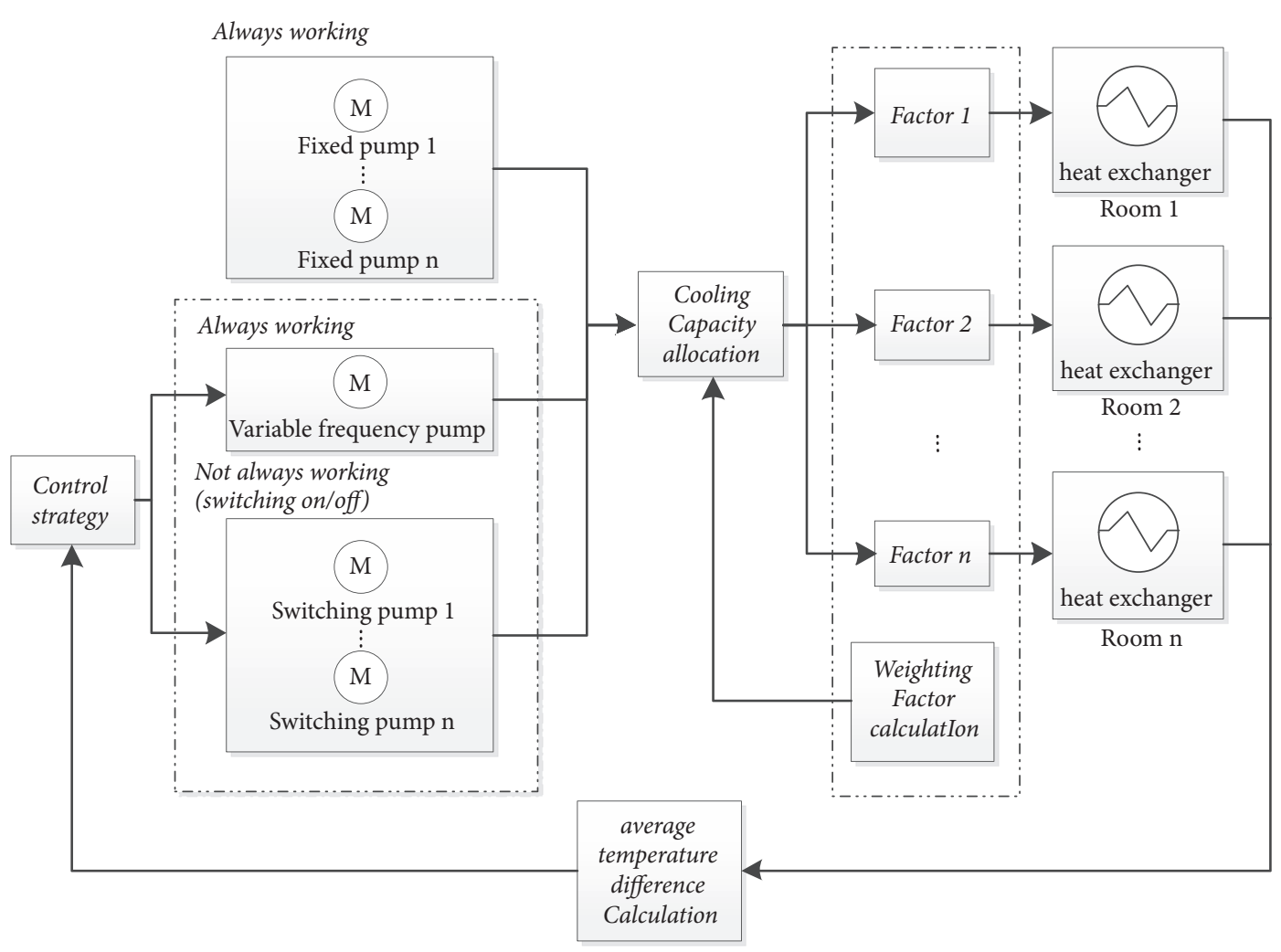

FIGURE 6: Cooling capacity allocation and average temperature methods. 


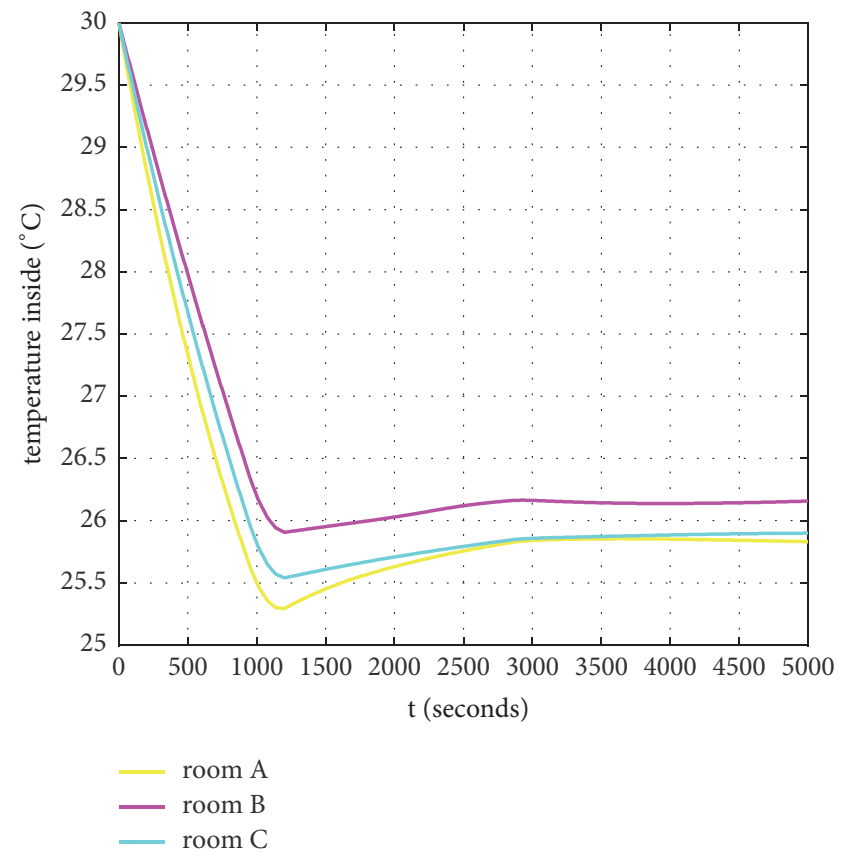

FIGURE 7: Inside temperature.

switching behaviour. Feedback control is used in the three rooms and the whole system, which adjusts the inside temperatures and water flow volume, respectively.

The inside temperatures of the three rooms started at $30^{\circ} \mathrm{C}$, and the system began at full capacity; in other words, all pumps were operating at rated power at the very start. Some curves were introduced into rooms as inside random cold loads; the surface temperatures of the wall space, window, and roof are set at constant values. The sending air volume was the same as the three rooms and was constant.

Figure 7 shows that the inside temperatures decline rapidly by the sending air. At approximately $\tau=1000 \mathrm{~s}$, the temperatures stabilise near the setting values, although the random cold loads disturb the system (Figure 8), and the total temperature difference is close to zero all for the three rooms (Figure 9). In addition, because of the lower cooling capacity requirements after $1000 \mathrm{~s}$, the total water flow volume falls, which is operating near the lowest flow volume (approximately 40\%); in other words, the water system realises a large potential space for energy saving (Figure 10). In the control process, the variable-frequency pump changes speed to alter the water volume in real-time by feedback control. In the first $1000 \mathrm{~s}$, the pump is operating at rated power; in the last approximately $2000 \mathrm{~s}$, the pump is operating in a fine adjustment status because of the real-time changing of cooling capacity requirements. In the middle period, the pump is operating at half the rated power. Switching pumps obey the control strategy and cooling capacity allocation methods, which adjust the number of operating switchable pumps (Figure 10). We set the threshold value $|H|=0.2$, and the total temperature difference leads to the switching situation shown in Figure 10.

Considering the electromagnetic properties, the speed of a pump starts from zero to a stable value with a smooth

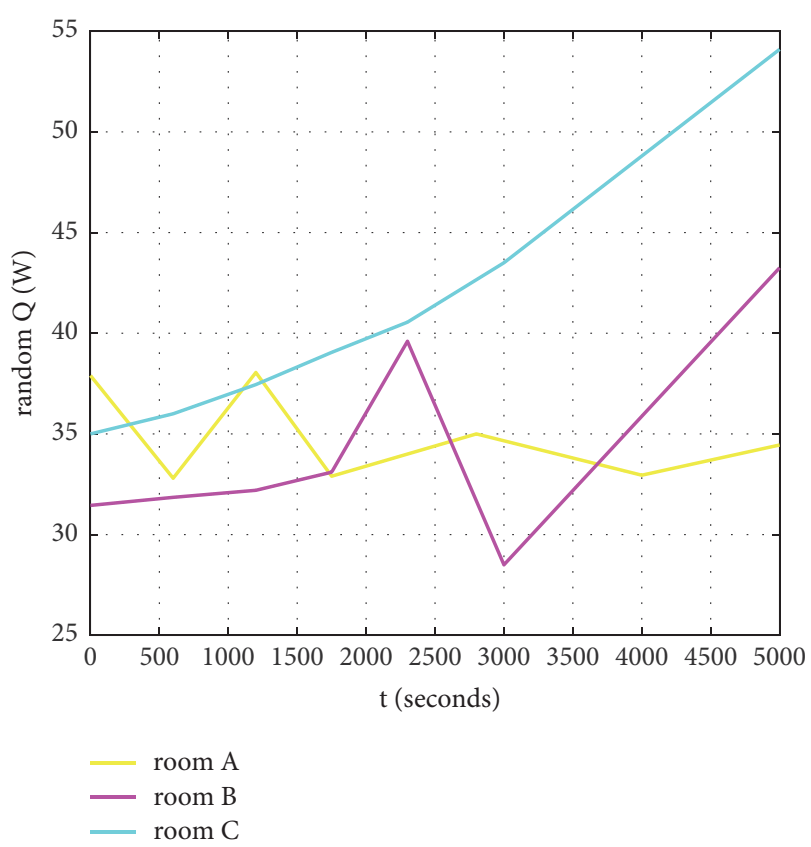

Figure 8: Random cold loads.

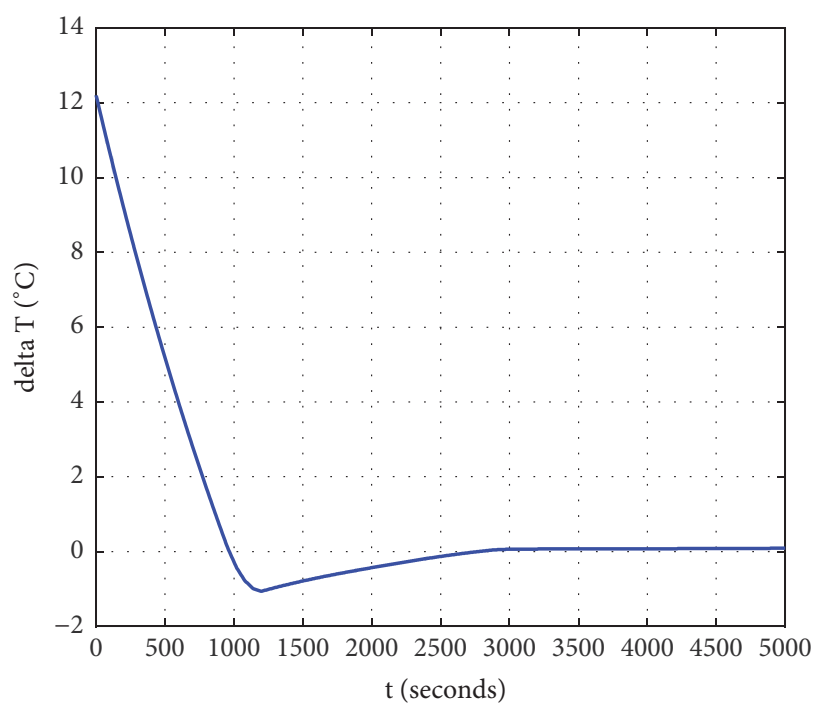

Figure 9: Total temperature difference.

curve (Figure 11); otherwise, it exhibits simply a horizontal line with a constant value. The torque responds according to the equation of motion, which shows the electromagnetic speed regulation process (Figure 12); otherwise, it exhibits a horizontal line as well. Considering the load characteristic in (17), the actual speed and torque responses do not show simple information. Figure 12 shows that the torque curve has acceleration and callback processes; after $0.2 \mathrm{~s}$, the torque stabilises at $19.6 \mathrm{~N} \cdot \mathrm{m}^{2}$, which is less than the rated load torque of $22 \mathrm{~N} \cdot \mathrm{m}^{2}$. The speed stabilises at $1273 \mathrm{rad} / \mathrm{m}$, somewhat less than the rated speed of $1350 \mathrm{rad} / \mathrm{m}$. The electromagnetic parameters are shown in Table 2.

By the power models of the pumps, the energy consumption was simulated (Figure 13); because of the variable 
TABLE 2: Electromagnetic parameters.

\begin{tabular}{lcr}
\hline Parameter & Value & Remark \\
\hline$n_{p}$ & 2 & variable-frequency pump \\
$r_{s}(\Omega)$ & 2.5 & variable-frequency pump \\
$J\left(\mathrm{~kg} \cdot \mathrm{m}^{2}\right)$ & 0.0012 & variable-frequency pump \\
$P_{b 0}(\mathrm{KW})$ & 2.8 & variable-frequency pump \\
$P_{g}(\mathrm{KW})$ & 1.5 & \\
$P_{s w}(\mathrm{KW})$ & 1.6 & variable-frequency pump \\
$T_{L 0}\left(\mathrm{~N} \cdot \mathrm{m}^{2}\right)$ & 22 & variable-frequency pump \\
$G$ & 2 & 0.9
\end{tabular}

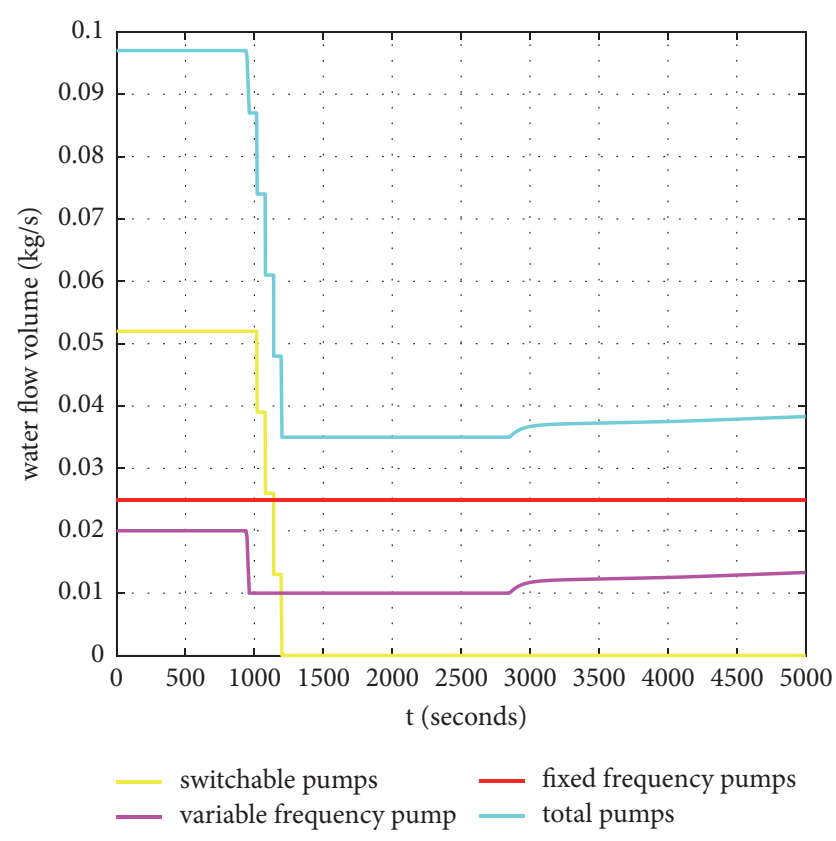

Figure 10: Water flow volume.

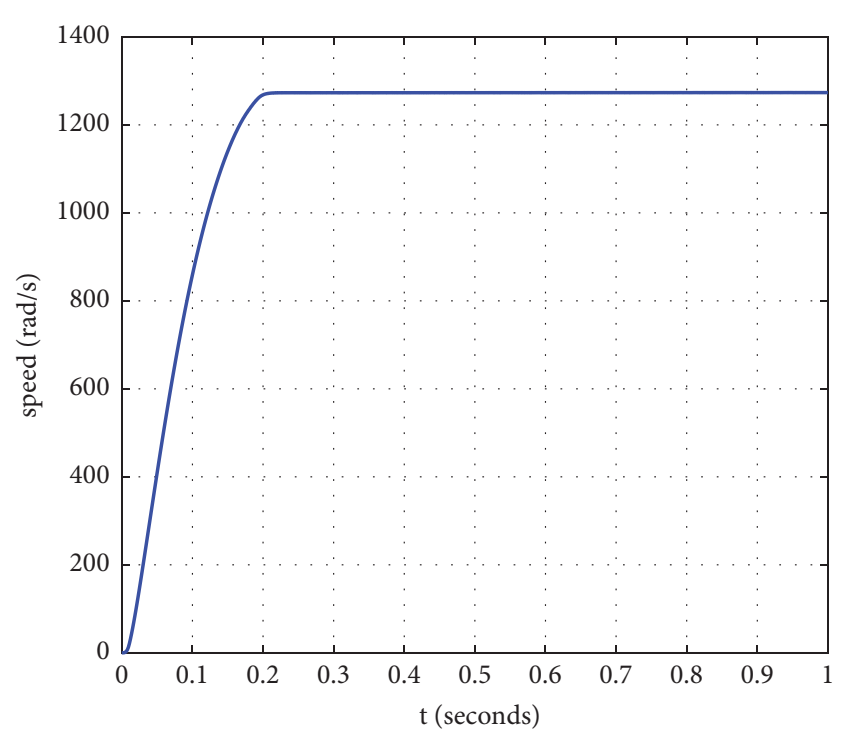

FIGURE 11: Speed of pump.

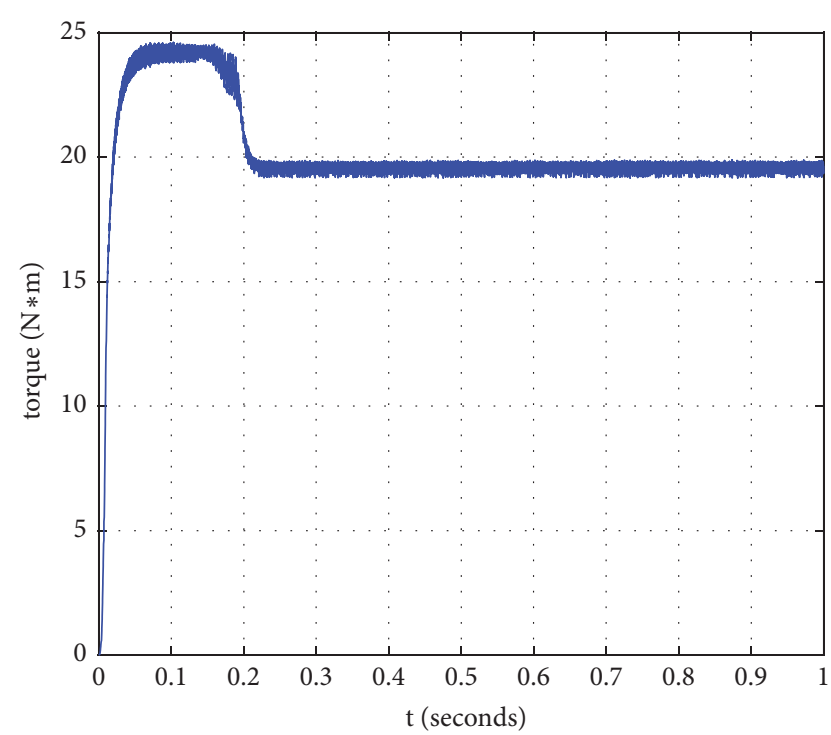

FIGURE 12: Electromagnetic torque.

water volume technology, the energy savings were calculated (Figure 14). It is obvious that, in the first $1000 \mathrm{~s}$, less energy savings is realised because of the cooling demand; however, after $1000 \mathrm{~s}$, large energy savings are shown according to the stabilised inside temperature. None of the switchable pumps operates after approximately $\tau=1000 \mathrm{~s}$; thus, the power consumption remains near $2 \mathrm{KWh}$. This is the same as the variable-frequency pump, which has a favourable adjustment due to the variable water flow. Figures 8 and 10 show that, even though some interference causes volume changes, the variable-frequency pump adjusts the water flow volume to play the roles of accuracy control and energy saving. After $5000 \mathrm{~s}$, the total energy consumption of the pumps is approximately $8.6 \mathrm{KWh}$.

The performance of systems controlled by hybrid dynamic control strategy and constant water volume technology (all the pumps work at rated power and the chilled water system works without using our control strategy), respectively, is shown in Figure 14. For constant water volume control technology, the total volume is always at $0.097 \mathrm{~kg} / \mathrm{s}$, the total power is always at $10.7 \mathrm{KW}$, and 


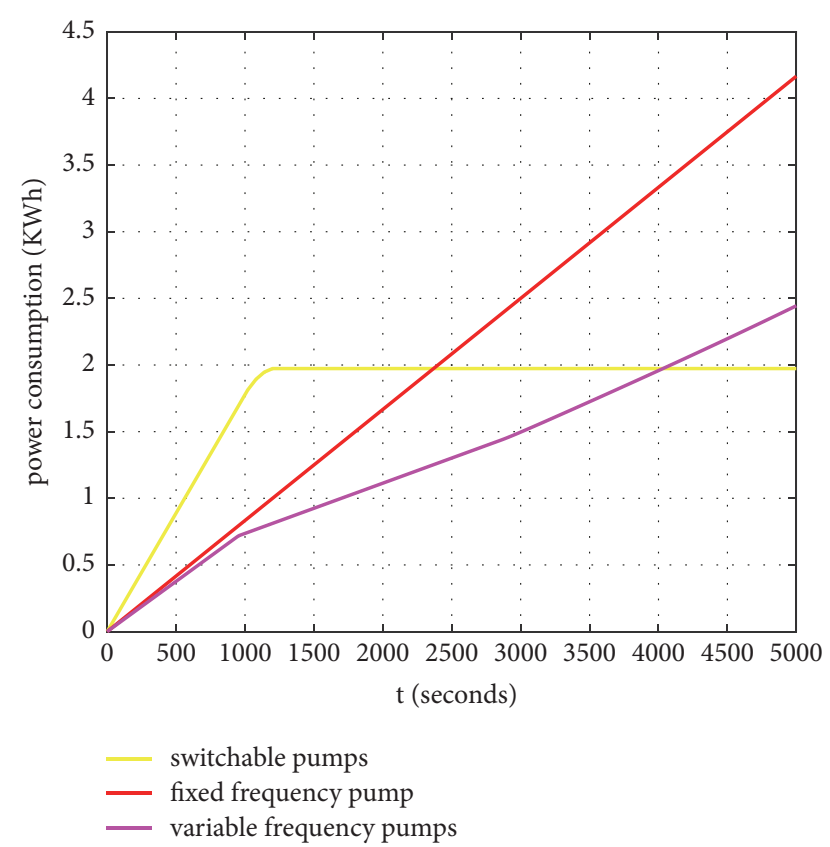

Figure 13: Power consumption.

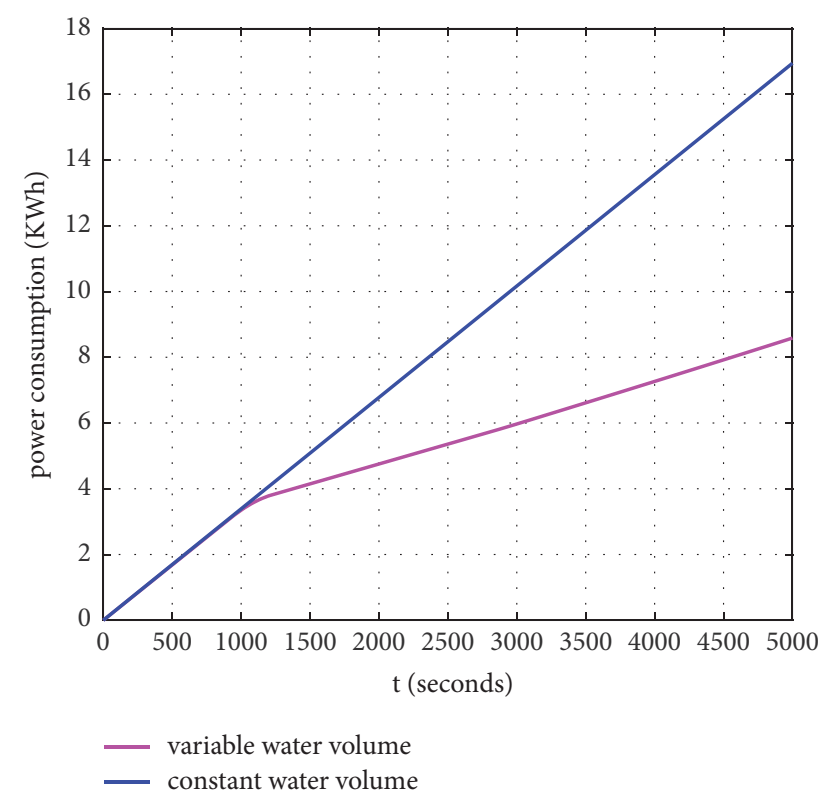

Figure 14: Power consumption comparison.

the whole energy consumption is up to approximately 17 $K W h$. Compared with the results of the system controlled by the hybrid dynamic control strategy, it can be found that the energy saving potential of the pumps has not been excavated in the constant water volume technique. In contrast, when the low cooling load level of the system is low, the pumps may reduce frequency or quit working for energy saving as presented in Figures 10 and 13. Consequently, the total energy consumption of the system control by the hybrid dynamical control method is approximately 8.6 KWh. The system exhibits $49.4 \%$ energy saving in $5000 \mathrm{~s}$ compared with that controlled by constant water volume scheme.

\section{Conclusions}

A hybrid dynamical approach to modelling and control is used in central air conditioning, which is a suitable approach for energy saving reconstruction in contemporary China. By analysing the cooling capacity transfer process from the chilled water system to the air system, the framework is built. By involving a direct torque control measure, the electromagnetic property is considered. For optimal hybrid control, the switching control strategy is developed; the cooling capacity allocation and average temperature methods are presented. On the basis of mathematical power models of pumps, the goal of accurate control and energy saving is realised. By simulation, a numeral example shows a hybrid control process and situation of energy savings. The approach saves $49.4 \%$ of water pump power consumption when compared with constant water volume technology. The modelling and control of multihybrid systems and their applications in refrigeration systems will be investigated in future works.

\section{Nomenclature}

$\begin{array}{ll}i: & \text { Current } \\ k: & \text { Amount } \\ m: & \text { Mass } \\ n: & \text { Speed } \\ n_{p}: & \text { Number of pole-pairs } \\ q: & \text { Flow volume } \\ R: & \text { Resistance } \\ u: & \text { Voltage } \\ A: & \text { Area } \\ C: & \text { Specific heat } \\ C_{Z}: & \text { Thermal capacity } \\ F: & \text { Factor of cooling capacity allocation } \\ G: & \text { Amount } \\ H: & \text { Constant } \\ J: & \text { Rotating inertia } \\ K_{f b}: & \text { Feedback coefficient (a room) } \\ K_{f b t}: & \text { Feedback coefficient (total system) } \\ K_{i}: & \text { Heat transfer coefficient } \\ P: & \text { Power } \\ Q: & \text { Heat } \\ R_{r}: & \text { Returned air rate } \\ S_{A B C}: & \text { Switch status signal } \\ T_{e}: & \text { Electromagnetic torque } \\ T_{L}: & \text { Load torque } \\ & \end{array}$

\section{Greek symbols}

$\varepsilon$ : Heat transfer efficiency

$\eta$ : Factor

$\Delta \theta$ : Temperature difference

$\theta:$ Temperature

$\theta_{j}$ : Surface temperature

$\Psi$ : Flux linkage

$\omega$ : Angular speed 


\section{Subscript}

$\begin{array}{ll}0: & \text { Rated } \\ A: & \text { Air } \\ B: & \text { Variable-frequency pump } \\ F: & \text { Fresh air } \\ f T: \text { Filter time } \\ G: \text { Fixed-frequency pump } \\ \text { ini: } \text { Initial } \\ i T: \text { Integral time } \\ j: \text { Surface (wall space, window, and roof) } \\ q r: \text { Latent heat } \\ r d: \text { Random } \\ r t: \text { Return } \\ s: \quad \text { Stator } \\ s a: \text { Sending air } \\ s e t: \text { Setting value } \\ s w: \text { Switchable pump } \\ s M: \text { M-axis of stator flux-oriented } \\ s T: \text { T-axis of stator flux-oriented } \\ w: \text { Water } \\ t t: \text { Total } \\ x r: \text { Sensible heat } \\ D C: \text { Busbar } \\ \psi: \text { Flux linkage. }\end{array}$

\section{Data Availability}

No data were used to support this study.

\section{Conflicts of Interest}

The authors declare that they have no conflicts of interest.

\section{Acknowledgments}

The research was supported by the National Natural Science Foundation of China (no. 40761104181).

\section{References}

[1] China Statistical Yearbook, China Statistical Publishing House, Beijing, China, 2015.

[2] J. Liang, B. Li, Y. Wu, and R. Yao, "An investigation of the existing situation and trends in building energy efficiency management in China," Energy and Buildings, vol. 39, no. 10, pp. 1098-1106, 2007.

[3] K. F. Fong, V. I. Hanby, and T. T. Chow, "HVAC system optimization for energy management by evolutionary programming," Energy and Buildings, vol. 38, no. 3, pp. 220-231, 2006.

[4] A. Keçebaş and I. Yabanova, "Thermal monitoring and optimization of geothermal district heating systems using artificial neural network: A case study," Energy and Buildings, vol. 50, pp. 339-346, 2012.

[5] T. Y. Zhao, J. L. Zhang, and L. D. Ma, "On-line optimization control method based on extreme value analysis for parallel variable-frequency hydraulic pumps in central air-conditioning systems," Building and Environment, vol. 47, pp. 330-338, 2012.

[6] D. Kaya, E. A. Yagmur, K. S. Yigit, F. C. Kilic, A. S. Eren, and C. Celik, "Energy efficiency in pumps," Energy Conversion and Management, vol. 49, no. 6, pp. 1662-1673, 2008.
[7] L. Lu, W. Cai, Y. S. Chai, and L. Xie, "Global optimization for overall HVAC systems-part I, problem formulation and analysis," Energy Conversion and Management, vol. 46, no. 7-8, pp. 999-1014, 2005.

[8] T. T. Chow, K. F. Fong, A. L. S. Chan, R. Yau, W. H. Au, and V. Cheng, "Energy modelling of district cooling system for new urban development," Energy and Buildings, vol. 36, no. 11, pp. 1153-1162, 2004.

[9] X. Sheng and L. Duanmu, "Electricity consumption and economic analyses of district heating system with distributed variable speed pumps," Energy and Buildings, vol. 118, pp. 291300, 2016.

[10] R. M. Lewis, V. Torczon, and M. W. Trosset, "Direct search methods: then and now," Journal of Computational and Applied Mathematics, vol. 124, no. 1-2, pp. 191-207, 2000.

[11] J. Sun and A. Reddy, "Optimal control of building HVAC\&R systems using complete simulation-based sequential quadratic programming (CSB-SQP)," Building and Environment, vol. 40, no. 5, pp. 657-669, 2005.

[12] M. Zaheer-Uddin and G. R. Zheng, "Optimal control of timescheduled heating, ventilating and air conditioning processes in buildings," Energy Conversion and Management, vol. 41, no. 1, pp. 49-60, 2000.

[13] L. Lu, W. Cai, Y. C. Soh, L. Xie, and S. Li, "HVAC system optimization - Condenser water loop," Energy Conversion and Management, vol. 45, no. 4, pp. 613-630, 2004.

[14] N. Nassif, S. Moujaes, and M. Zaheeruddin, "Self-tuning dynamic models of HVAC system components," Energy and Buildings, vol. 40, no. 9, pp. 1709-1720, 2008.

[15] I.-H. Yang, M.-S. Yeo, and K.-W. Kim, "Application of artificial neural network to predict the optimal start time for heating system in building," Energy Conversion and Management, vol. 44, no. 17, pp. 2791-2809, 2003.

[16] S. Wang and J. Burnett, "Online adaptive control for optimizing variable-speed pumps of indirect water-cooled chilling systems," Applied Thermal Engineering, vol. 21, no. 11, pp. 1083-1103, 2001.

[17] M. Anderson, M. Buehner, P. Young et al., "An experimental system for advanced heating, ventilating and air conditioning (HVAC) control," Energy and Buildings, vol. 39, no. 2, pp. 136147, 2007.

[18] S. Qu, Z. Sun, H. Fan, and K. Li, "BP neural network for the prediction of urban building energy consumption based on Matlab and its application," in Second International Conference on Computer Modeling and Simulation, pp. 263-267, IEEE, Sanya, Hainan, China, 2010.

[19] L. Lu, W. J. Cai, L. Xie, S. Li, and Y. C. Soh, "HVAC system optimization-in-building section," Energy and Buildings, vol. 37, no. 1, pp. 11-22, 2005.

[20] Z. Ma and S. Wang, "An optimal control strategy for complex building central chilled water systems for practical and realtime applications," Building and Environment, vol. 44, no. 6, pp. 1188-1198, 2009.

[21] D.-C. Gao, S. Wang, and Y. Sun, "A fault-tolerant and energy efficient control strategy for primary-secondary chilled water systems in buildings," Energy and Buildings, vol. 43, no. 12, pp. 3646-3656, 2011.

[22] X. Sheng and D. Lin, "Energy saving analyses on the reconstruction project in district heating system with distributed variable speed pumps," Applied Thermal Engineering, vol. 101, pp. 432445, 2016. 


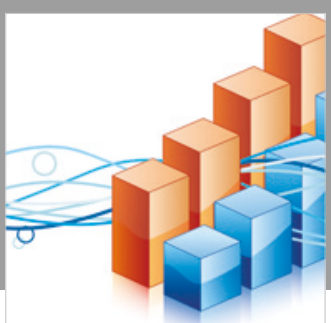

Advances in

Operations Research

\section{-n-m}
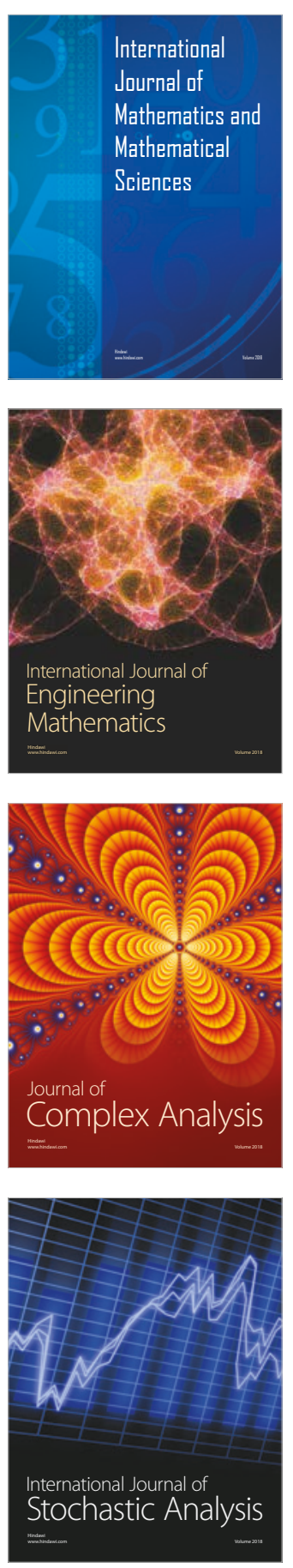
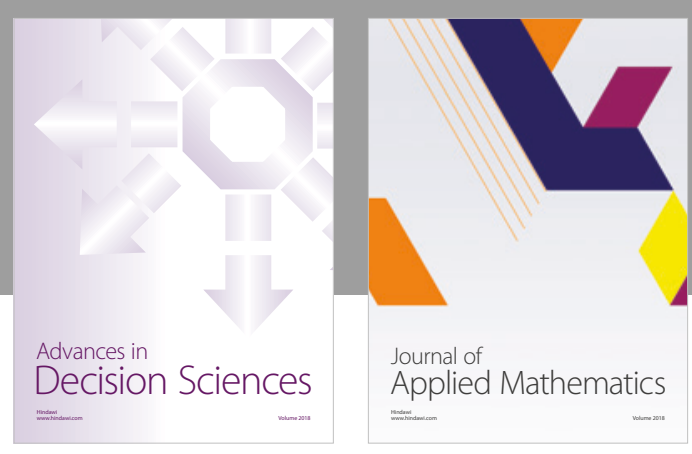

Journal of

Applied Mathematics
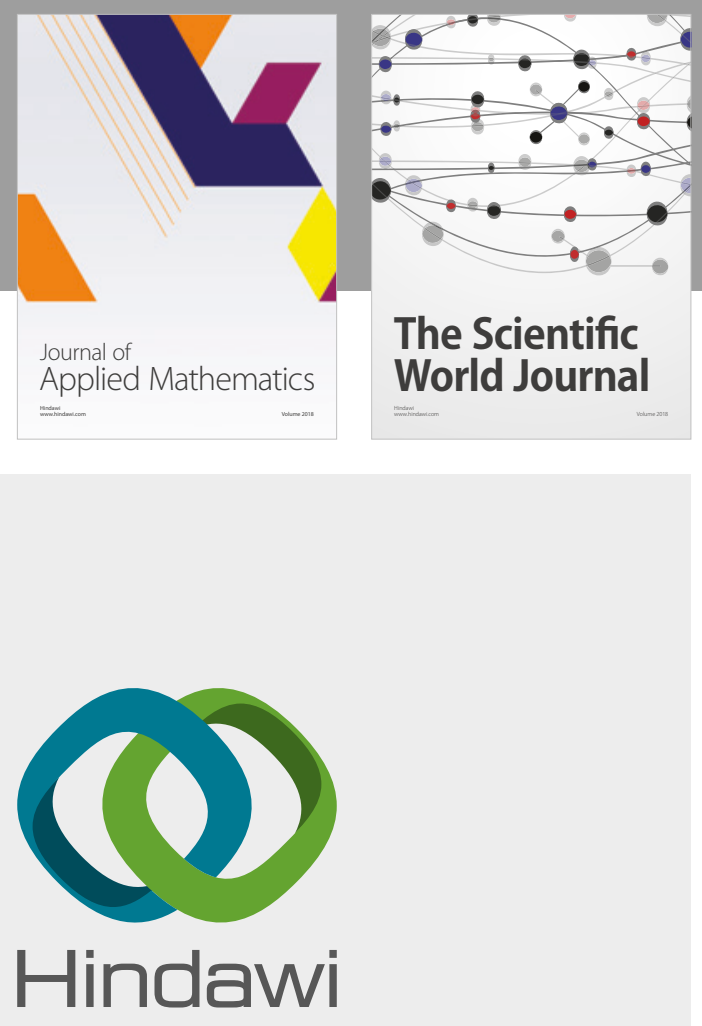

Submit your manuscripts at

www.hindawi.com

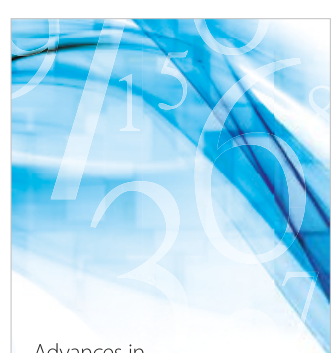

Advances in
Numerical Analysis
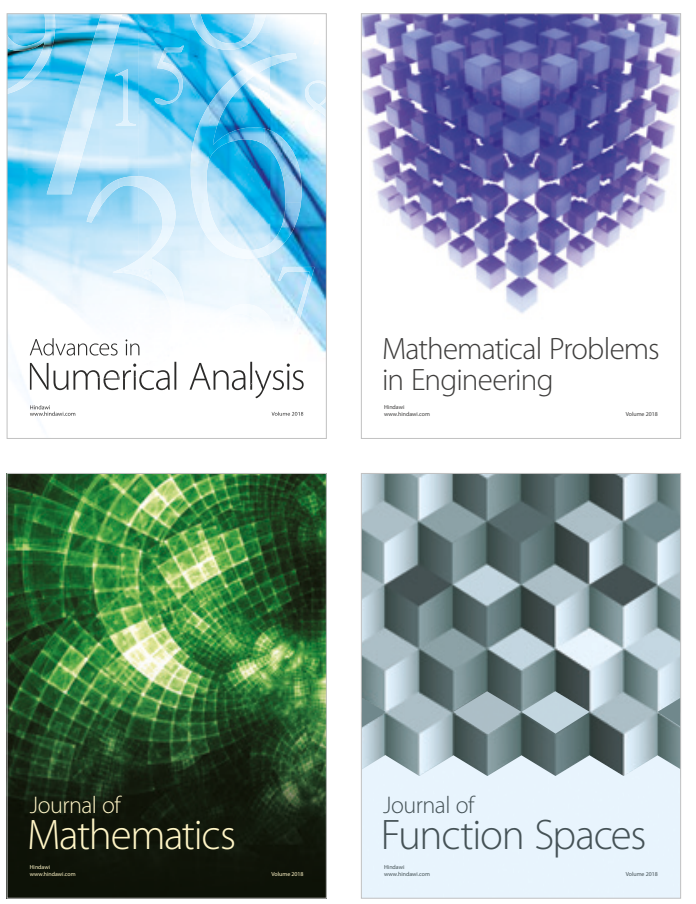

Mathematical Problems in Engineering

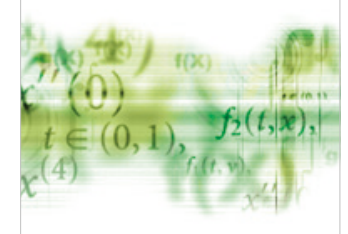

International Journal of

Differential Equations

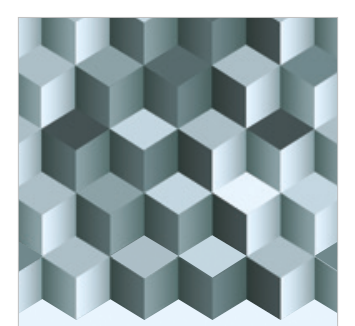

Journal of

Function Spaces

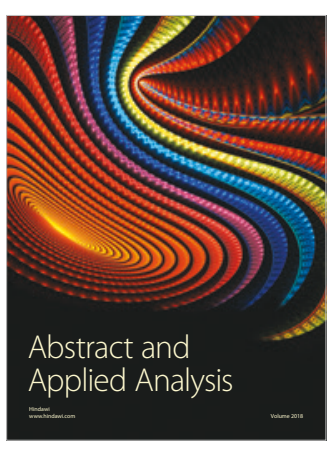

The Scientific

World Journal

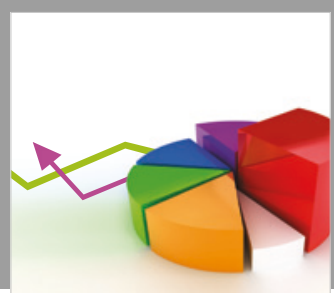

Journal of

Probability and Statistics
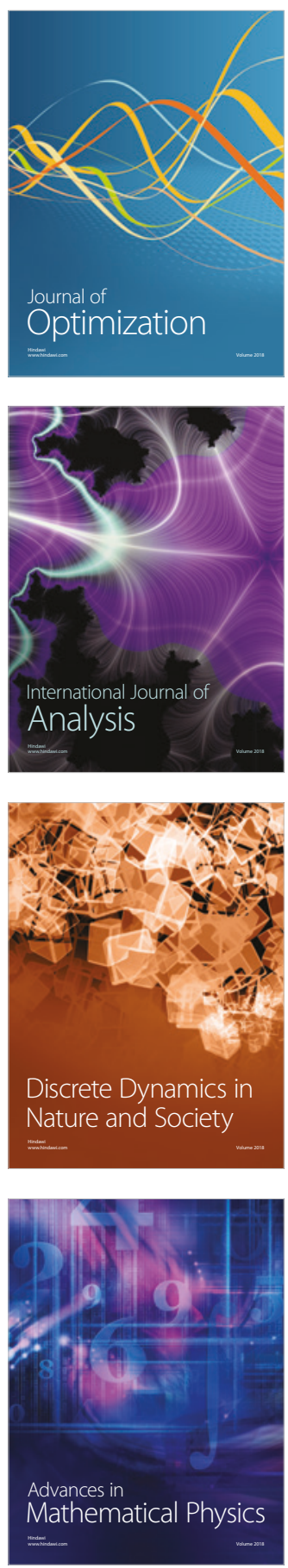